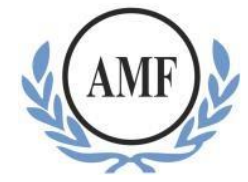

\title{
Cada Tampinha, uma Dose de Esperança: um Estudo de Caso do Projeto Tampinha Paratleta Assampar
}

\author{
Luciane Schramm de Freitas ${ }^{1}$ \\ Thiago Kader Rajeh Ibidaiwi ${ }^{2}$ \\ Marcelo Pastoriza Tatsch ${ }^{3}$ \\ Miguel Augusto Bauermann Brasil ${ }^{4}$
}

\begin{abstract}
Resumo: Sem dúvidas, a educação ambiental é considerada um instrumento na sensibilização das pessoas e das organizações, sendo fundamental para que as políticas ambientais funcionem de forma eficiente. Assim, o presente estudo tem como foco demonstrar as ações desenvolvidas pela ASSAMPAR, em seu projeto Tampinha Paratleta, cujo objetivo é conscientizar a população sobre a reutilização e as possibilidades que um simples gesto pode trazer à sociedade. Nesse sentido, a presente pesquisa visou a identificar as razões que levaram a ASSAMPAR a criar essa ação e quais fatores levam as pessoas a aderirem a essa nobre causa. A pesquisa foi realizada com escolas privadas na cidade de Santa Maria/RS, juntamente com seus gestores, para verificar se os princípios norteadores da educação ambiental estavam presentes quando aderiram à campanha. Os resultados demonstram que o projeto apresenta um enorme crescimento na adesão à campanha, onde pode-se perceber que a Educação Ambiental (EA) é um processo de ensino, de transmissão de informação e de sensibilização das pessoas acerca das questões ambientais, as quais estão fortemente presentes no projeto desenvolvido pela ASSAMPAR.
\end{abstract}

\footnotetext{
${ }^{1}$ Bacharela em Administração pela SOBRESP - Faculdade de Ciências da Saúde. E-mail:

lu.almox.ufsm@gmail.com.

${ }^{2}$ Doutorando em Extensão Rural pela Universidade Federal de Santa Maria (UFSM); Mestre em Engenharia de Produção (UFSM); Especialista em Recursos Humanos e Marketing pela Faculdade Metodista de Santa Maria (FAMES); Bacharel em Administração de Empresas com Habilitação em Comércio Exterior (FAMES); Diretor Acadêmico e professor da Faculdade de Ciências da Saúde (SOBRESP); Consultor de Negócios na ARHAT Soluções Empresariais Integradas; tem experiência na área de Administração com ênfase em Negócios Internacionais, atuando principalmente nos seguintes temas: marketing, gestão ambiental, responsabilidade social, sustentabilidade, empreendedorismo social. E-mail: thiagokader@hotmail.com.

${ }^{3}$ Experiência profissional no setor privado, com ênfase em Gestão de Negócios, com mais de 20 anos de experiência em liderança de equipes em empresas dos setores consultoria organizacional, de construção civil e concessionárias de automóveis; início da atividade no ensino superior em 2008, na Universidade Luterana do Brasil (Santa Maria), nos cursos de graduação em Administração, Estética e Cosmetologia e Direito e, no curso de pós-graduação em Estética e Cosmetologia; Em 2010 contratado pela Faculdade Metodista de Santa Maria-FAMES, onde atuou nos cursos de graduação em Administração de Empresas e Contabilidade e pós-graduação em Gestão de Pessoas e Marketing pela mesma instituição, com as disciplinas nas áreas de gestão da produção e operações, planejamento estratégico, empreendedorismo, de qualidade e produtividade, logística e gestão de pessoas, entre outros. Foi membro do Conselho de Administração do Curso e do CEPE da FAMES. Participou como conferencista convidado no MBA Executivo em Finanças e Banking em 2012 e 2013 para a disciplina de gerenciamento de projetos na FAPAS. Contratado em 2013 pela UFSM, como professor substituto vinculado ao curso de Administração e participação em cursos de Gestão de Agronegócios, Turismo e Gestão Ambiental no Campus-RS Silveira Martins. Contrato junto à Faculdade Antonio Meneghetti, vinculado ao Curso de Administração (março de 2015). E-mail: tatsch.marcelo@gmail.com.

${ }^{4}$ Possui graduação em Sistemas de Informação pela Universidade Franciscana (2008), licenciatura plena em informática e Mestrado em Ciência da Computação pela Universidade Federal de Santa Maria - UFSM (Área de Computação Aplicada). Atualmente trabalha como Professor efetivo no Colégio Técnico Industrial na UFSM e Coordenador Técnico do Escritório de Projetos EcoAGILE - CTISM/UFSM. Atua também como analista e desenvolvedor de Software Pleno possuindo mais de 10 anos de experiência na atividade. Tem experiência na área de Sistemas de Informação com ênfase nas áreas de engenharia de software, melhoria de processos de software e programação web. E-mail: miguelbrasil@ctism.ufsm.br.
} 
Palavras-Chave: Projeto Tampinha Paratleta; Responsabilidade Social; Educação Ambiental.

Each Little Bottle Tap, a Dose of Hope: a Case Study of the Tampinha Paratleta Assampar Project

\begin{abstract}
Undoubtedly, environmental education is considered an instrument to raise awareness among people and organizations, and it is essential for environmental policies to function efficiently. Thus, the present study focuses on demonstrating the actions developed by ASSAMPAR, in its Tampinha Paratleta Project, whose objective is to raise awareness of the population about reuse and the possibilities that a simple gesture can bring to society. In this sense, this research aimed to identify the reasons that led ASSAMPAR to create this action and what factors lead people to adhere to this noble cause. The research was conducted with private schools in the city of Santa Maria/ RS, together with their managers, to verify if the guiding principles of environmental education were present when they joined the campaign. The results show that the project presents a huge growth in adherence to the campaign, where it can be perceived that Environmental Education (EA) is a process of teaching, transmitting information and sensitizing people about environmental issues, which are strongly present in the project developed by ASSAMPAR.

Keywords: Tampinha Paratleta Project; Social Responsibility; Environmental Education.
\end{abstract}

Cada Tampinha, una dosis de esperanza: un caso de estudio del proyecto Capinha Paratleta Assampar

Resumen: Sin duda, la educación ambiental se considera un instrumento para sensibilizar a las personas y las organizaciones, y es esencial que las políticas ambientales funcionen de manera eficiente. Así, el presente estudio se centra en demostrar las acciones desarrolladas por ASSAMPAR, en su Proyecto Tampinha Paratleta, cuyo objetivo es sensibilizar a la población sobre la reutilización y las posibilidades que un simple gesto puede aportar a la sociedad. En este sentido, esta investigación tenía como objetivo identificar las razones que llevaron a ASSAMPAR a crear esta acción y qué factores llevan a las personas a adherirse a esta noble causa. La investigación se llevó a cabo con escuelas privadas en la ciudad de Santa María / RS, junto con sus gerentes, para verificar si los principios rectores de la educación ambiental estaban presentes cuando se unieron a la campaña. Los resultados muestran que el proyecto presenta un enorme crecimiento en la adhesión a la campaña, donde se puede percibir que la Educación Ambiental (EA) es un proceso de enseñanza, transmisión de información y sensibilización a la gente sobre temas ambientales, que están fuertemente presentes en el proyecto desarrollado por ASSAMPAR.

Palabras clave: Proyecto Tampinha Paratleta; Responsabilidad Social; Educación Ambiental.

\title{
1 Introdução
}

As questões ambientais, como a degradação de recursos naturais e da biodiversidade, infundem a sociedade na participação e na busca de novas formas de pensar e agir. Dessa maneira, buscam-se novos modelos produtivos, os quais possam prover as necessidades humanas e as relações sociais, garantindo, assim, o equilíbrio entre homem e a natureza.

Desde o final do século passado, os impactos ambientais se tornaram mais acentuados devido ao elevado crescimento demográfico e ao alto grau da aceleração tecnológica. A partir dos anos 70, surgiu uma maior preocupação do governo, organizações não governamentais e sociedade em se discutir e implementar políticas voltadas para o planejamento e gestão ambiental em todo o mundo (DAL FORNO, 2017).

De modo geral, a preocupação com a conservação e a preservação da qualidade 
ambiental vem se revertendo como um tema cada vez mais importante e presente na vida dos cidadãos. Todos esses problemas fizeram com que o homem revisse sua postura em relação ao usufruto dos recursos naturais que o cercam. Essa preocupação materializou-se através de uma série de eventos induzidos por uma maior percepção dos problemas ambientais, que levaram ao amadurecimento dos conceitos de desenvolvimento sustentável, educação ambiental e sustentabilidade (SEIFFERT, 2011).

A Associação Santa-Mariense Paradesportiva (ASSAMPAR) foi criada em novembro de 2016 com o intuito de promover a inclusão social por meio dos esportes adaptados e, também, a questão da acessibilidade na cidade de Santa Maria/RS.

Nesse contexto, as organizações e a sociedade tornam-se peças fundamentais na busca do desenvolvimento da sustentabilidade frente aos impactos causados pelas suas atividades ao patrimônio natural. Assim sendo, o presente trabalho tem como ênfase estudar o projeto desenvolvido pela ASSAMPAR, que tem vinculado entre seus projetos o "Tampinha Paratleta", o qual foi lançado no ano de 2018, mais especificamente em 16 de fevereiro, cujo objetivo central é criar uma conscientização na população santa-mariense quanto ao descarte de tampinhas plásticas e lacres de alumínio.

É importante salientar que o recolhimento desses produtos (tampinhas e lacres) se torna um meio econômico para manter o projeto paradesportivo da associação. Além do contexto econômico, tal projeto contempla-se nos eixos social, em que busca criar um senso ecológico em todos os participantes, e senso ambiental, dando o destino correto a esses resíduos. Entende-se, portanto, que sustentabilidade, em seu sentido pleno, é a capacidade de se sustentar, de se manter, em consonância com o meio em que se vive (LEFF, 2011).

Desse modo, o presente estudo tem como problema de pesquisa: De que forma o projeto "Tampinha Paratleta", desenvolvido pela ASSAMPAR, pode contribuir para o contexto socioambiental da comunidade santa-mariense? Como objetivo geral, identificar quais são as principais contribuições que o projeto "Tampinha Paratleta" traz para o contexto socioambiental da comunidade de Santa Maria/RS. E como objetivos específicos visa a: a) descrever como ocorrem as ações realizadas pelo projeto; b) verificar quais são as contribuições socioambientais que o projeto proporciona à comunidade atendida; e c) verificar a percepção das escolas privadas da cidade de Santa Maria/RS com relação ao projeto.

A importância e a relevância desse estudo se dá em contribuir com a sociedade e a literatura acerca dos temas educação ambiental, sustentabilidade e responsabilidade social. Ademais, sabe-se que esses assuntos geram uma preocupação crescente, uma vez que os recursos naturais estão cada vez mais ameaçados em consequência do comportamento 
humano frente à sua utilização. Desse modo, ficam evidentes os impactos negativos que o homem provoca na natureza, onde a poluição, o acúmulo de resíduos sólidos e a diminuição rápida da biodiversidade são, apenas, alguns dos exemplos dos problemas ambientais enfrentados na atualidade.

A educação ambiental, entre outras propostas, aborda as questões sociais em inúmeros aspectos, fazendo uma ligação entre a relação do ser humano consigo mesmo, com o meio ambiente e seus componentes. Enfatizando, ainda, a existência de vínculos inter-relacionados entre as questões sociais, econômicas, políticas e ambientais, onde são concebidas práticas culturais elaboradas e constituídas em torno de problemas concretos, estando, assim, cada vez mais presente nas ações educativas das escolas e universidades (BARBIERI, 2011).

Vale salientar que a deterioração do ambiente, o risco de colapso ecológico e o avanço da desigualdade e da pobreza são sinais expressivos da crise socioambiental no mundo. Com isso, a sustentabilidade é o significante de uma falha na história da humanidade, tornando-se o tema do tempo atual, do final do século XX e da passagem para o terceiro milênio; da transição da modernidade incompleta para uma pós-modernidade incerta, marcada pela diferença, pela diversidade, pela democracia e pela autonomia (LEFF, 2011).

Por conseguinte, o desenvolvimento sustentável necessita do planejamento e da participação de todas as esferas da população. É essencial analisar cuidadosamente o quanto já foram gastos dos recursos e quanto ainda resta, visto que os recursos naturais estão acabando e seu uso consciente é fundamental para não comprometer a vida das futuras gerações.

Diante disso, esse estudo tem, enquanto relevância acadêmica e social, o intuito de destacar a importância da responsabilidade socioambiental no ambiente escolar, com ênfase nas escolas privadas do ensino básico ao ensino médio. E, assim, verificar como as escolas estão trabalhando com os aspectos ambientais em suas bases curriculares é um dos principais tópicos dessa pesquisa.

O presente estudo está estruturado em cinco sessões: a primeira descreve a introdução, seguida da problemática do estudo e seus objetivos; a segunda sessão apresentará o método para o alcance dos objetivos; na sequência, terceira sessão, abordarse-á a revisão da literatura, que deu suporte à análise dos resultados; já nas sessões finais, quatro e cinco, abordar-se-ão a análise dos resultados e as considerações finais.

\section{Fundamentação Teórica}


Para fundamentar a proposta deste estudo, o presente item apresenta a pesquisa realizada na literatura acerca dos seguintes temas: gestão ambiental, desenvolvimento sustentável e sustentabilidade.

\subsection{Gestão Ambiental, desenvolvimento histórico}

Devido ao desenvolvimento industrial no final do século XIX, nos Estados Unidos e na Europa Continental, e ao desenvolvimento do capitalismo nas primeiras décadas do século $\mathrm{XX}$, os quais resultaram no surto industrial que permanece até os dias atuais, surgem os primeiros trabalhos sobre os efeitos da poluição gerada por minas e fábricas, basicamente tratados sob o enfoque da saúde dos trabalhadores. É nessa época que surgem as primeiras preocupações da população com a crescente degradação ambiental, provocada pela ação humana em esfera mundial (TACHIZAWA, 2011).

De acordo com Dias (2011), ainda nos primórdios da industrialização, o economista inglês Thomas Robert Malthus (1766 - 1834) publicou um trabalho denominado "Ensaio sobre a população: como afeta o futuro progresso da humanidade" (1798), no qual destacava a preocupação para os problemas decorrentes do aumento populacional e para a possibilidade de esgotamento dos recursos naturais e seus reflexos no crescimento econômico. Dando destaque ao crescimento populacional, afirmava que o poder da população é infinitamente maior que o da Terra para produzir a subsistência do homem. O autor defende, ainda, que a problemática ambiental, hoje, é uma preocupação crescente nos encontros mundiais e na maioria das empresas que não desejam fazer papel de vilãs da sociedade.

Para Campaner et al. (2009), há algumas décadas, as pessoas compreenderam que a preservação do planeta era significado também da preservação da própria vida. Hoje, a sociedade reconhece a gravidade da crise ambiental que alcançou uma escala planetária, não sendo apenas decorrente de ações irresponsáveis de alguns, mas reflexo do modelo de desenvolvimento.

Dessa maneira, tornou-se necessária e urgente a elaboração de um projeto de união das ciências de gestão, devido ao evidente desequilíbrio nos ecossistemas terrestres, com intuito de desenvolver os instrumentos daquilo que se denomina gestão ambiental. No entanto, a complexidade das questões ambientais aumenta as necessidades e a importância de ações de todos os setores da gestão do meio ambiente para a busca de soluções integradas e sustentáveis (JR. PHILIPPI e PELICIONI, 2005).

Verifica-se, assim, a preocupação das empresas e instituições em realizar práticas e programas inovadores de gerenciamento ecológico, o qual envolve a passagem do 
pensamento mecanicista para o pensamento sistêmico. E por meio dessa mudança é que a percepção do mundo, como máquina, cede lugar à percepção do mundo como sistema vivo (ANDRADE; TACHIZAWA e CARVALHO, 2006). Dessa forma, emerge o conceito e a preocupação com a gestão ambiental.

\subsubsection{Conceito de Gestão Ambiental}

Entende-se que a gestão ambiental representa uma importante ferramenta de competitividade nos diversos setores das organizações produtivas, ocasionando mudanças de comercialização e consumo. A partir de então, surge a necessidade de construção de procedimentos sistemáticos, a fim de gerenciar e controlar as ações sobre o meio ambiente. Pode-se, dentre eles, destacar o Sistema de Gestão Ambiental (SGA), caracterizado por um conjunto de ações visando ao planejamento, à organização, ao controle e à minimização dos impactos ambientais causados pelos processos produtivos (DAL FORNO, 2017).

De acordo com Dias (2011, p. 102), a "gestão ambiental é a gestão cujo objetivo é conseguir que os efeitos ambientais não ultrapassem a capacidade de carga do meio onde se encontra a organização, ou seja obter-se um desenvolvimento sustentável”. Segundo

Barbieri (2011), a administração do meio ambiente ou gestão ambiental relaciona-se às diretrizes e às atividades administrativas como planejamento, direção, controle e alocação de recursos e outras atividades realizadas. Isso tudo a fim de obter efeitos positivos sobre o meio ambiente, evitando ou eliminando os problemas causados pelas ações da organização.

Vale dizer que a gestão ambiental requer conhecimento e planejamento de seu desenvolvimento, tornando-se um convite aos cidadãos para participar na produção de suas condições de existência e em seus projetos de vida. Somado a isso, oferecer novos princípios aos processos de democratização da sociedade, induzindo a participação direta

das comunidades na apropriação e transformação dos recursos ambientais a fim de que haja uma preocupação com o desenvolvimento ambiental (LEFF, 2011).

\subsection{Desenvolvimento Sustentável e Sustentabilidade}

De acordo com Barbosa (2008), o termo desenvolvimento sustentável surgiu a partir de estudos da Organização das Nações Unidas sobre as mudanças climáticas como resposta à crise social e ambiental enfrentada pela humanidade a partir da segunda metade do século XX. Na Comissão Mundial para o Meio Ambiente e Desenvolvimento (CMMAD), também conhecida como Comissão de Brundtland, presidida pela norueguesa Gro Haalen Brundtland, no processo preparatório à Conferência das Nações Unidas, 
também chamada de Rio 92, foi desenvolvido um relatório que ficou conhecido como Nosso Futuro Comum. Durante três anos de pesquisa e análise, esse relatório apresentou informações sobre as questões sociais, principalmente no que se refere ao uso da terra, sua ocupação, suprimento de água, abrigo e serviços sociais, educativos e sanitários, além de administração do crescimento urbano. Além disso, apresenta, também, uma das definições mais difundidas do conceito: “o desenvolvimento sustentável é aquele que atende às necessidades do presente sem comprometer as possibilidades de as gerações futuras atenderem suas próprias necessidades" (BARBOSA, 2008, p. 3).

Entende-se que o processo de gestão ambiental surgiu como uma alternativa para buscar a sustentabilidade dos ecossistemas. Os conceitos de gestão ambiental e desenvolvimento sustentável criaram-se durante as últimas décadas, porém ainda não assumiram uma configuração definitiva (SEIFFERT, 2011).

Alencastro (2012) afirma que o desenvolvimento sustentável intenciona o equilíbrio entre o desenvolvimento econômico, o meio ambiente e as questões sociais, tornando-se um processo contínuo de melhoria das condições de vida e minimizando o uso dos recursos naturais, sem causar danos ou desequilíbrio ao ecossistema. Para que o desenvolvimento sustentável seja atingido, uma das conceituações mais utilizadas atualmente é o Triple Bottom Line, conforme demonstra a Figura 1.

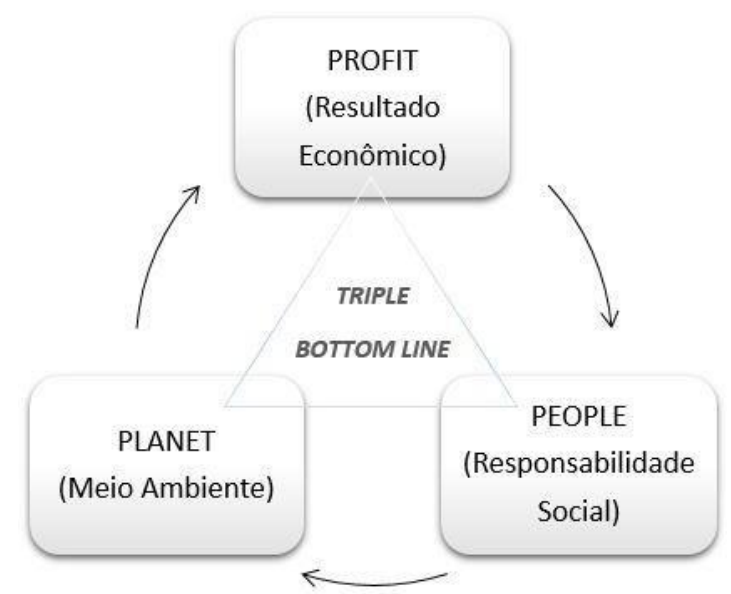

Figura 1: Triple Bottom Line. Fonte: Adaptado de Alencastro, (2012).

De acordo com Oliveira et al. (2012), o conceito do Triple Bottom Line, analisandoos separadamente, define-se como: Econômico (Profit), cujo propósito é a criação de 
empreendimentos possíveis e chamativos para os investidores; Ambiental (Planet), o qual tem como objetivo analisar a interação de processos com o meio ambiente sem que esses lhe causem danos permanentes; e social (People), que se preocupa com a formação de ações justas para trabalhadores, parceiros e sociedade.

O Triple Bottom Line, também conhecido como 3 Ps (Profit, Planet e People), representa um conjunto de valores, objetivos e processos que uma organização deve destacar para criar valor nas dimensões econômica, social e ambiental, conhecido no Brasil como tripé da sustentabilidade, podendo ser aplicado tanto nos eixos macro, para um país ou o próprio planeta, como micro, em uma residência, empresa, escola ou pequena vila (DIAS, 2011).

Para Sartori, Latrônico e Campos (2014), existe ainda uma falta de consenso sobre os termos desenvolvimento sustentável e sustentabilidade, pelo fato de que a sustentabilidade é usada para descrever os processos e atividades. Por conseguinte, o desenvolvimento sustentável se concentra principalmente nas pessoas e seu bem-estar, não obstante permaneçam diversas compreensões. A sustentabilidade e o desenvolvimento sustentável objetivam transpor, para as gerações futuras, um estoque de capital que é, pelo menos, tão grande quanto o que a geração atual herdou das gerações anteriores.

Ao se definir desenvolvimento sustentável, também se discute o que é sustentabilidade. Segundo Barbosa (2008), sustentabilidade significa a possibilidade de se obterem continuamente condições iguais ou superiores de vida para um grupo de pessoas e seus sucessores em dado ecossistema. Apresentadas as bases de sustentação teóricas deste estudo, será abordado, no próximo capítulo, o método a ser adotado para atingir os objetivos propostos.

\section{Método}

Metodologia científica é o estudo sistemático e lógico dos métodos empregados nas ciências, seus fundamentos, sua validade e sua relação com as teorias científicas. Normalmente, o método científico compreende, sobretudo, um conjunto de dados iniciais e um sistema de operações ordenadas adequado para a formulação de conclusões, de acordo com certos objetivos predeterminados (GERHARDT; SILVEIRA, 2009). Neste capítulo, serão abordados os procedimentos metodológicos a serem adotados nesta pesquisa. 
É relevante destacar que este estudo tem como base uma pesquisa bibliográfica e descritiva, visando a alcançar os objetivos que foram propostos. A pesquisa de natureza descritiva tem "como objetivo primordial a descrição das características de determinada população ou fenômeno ou, então, o estabelecimento de relação entre variáveis" (GIL, 2007, p. 42), e a pesquisa bibliográfica é feita a partir do levantamento de referências teóricas já analisadas e publicadas por meios escritos e eletrônicos, como livros, artigos científicos, páginas de websites. Ainda na visão de Gil (2007), os modelos mais simbólicos desse tipo de pesquisa são sobre verificações, ideologias ou aquelas que se indicam à análise das diversas posições acerca de um problema.

Com o intuito de responder aos objetivos propostos, o presente estudo realizou uma pesquisa de cunho qualitativa com a utilização do método estudo de caso. Para Dalfovo, Lana e Silveira (2008), a pesquisa qualitativa desenvolve a coleta e análise de texto (falado e escrito) e a observação direta do comportamento, a qual não envolve a quantificação dos acontecimentos. O estudo de caso, segundo Fonseca (2002), pode ser caracterizado como um estudo de uma entidade estabelecida, sugerindo conhecer em profundidade uma determinada situação. Buscando mostrar o que há de mais essencial e característico nela, o pesquisador buscou não intervir sobre o objeto a ser estudado, mas revelá-lo tal como ele o percebe.

A ASSAMPAR é uma associação paradesportiva, cujo intuito é promover projetos e atividades que possam beneficiar a inclusão social, que surgiu da necessidade de integrar, entre si e na sociedade, crianças, adolescentes e adultos com deficiência física, através dos esportes adaptados individuais ou coletivos. A associação tem, entre as suas atividades, os seguintes esportes: basquete em cadeira de rodas, handebol, corrida de rua, bocha paralímpica, paracanoagem, tênis de mesa, tiro esportivo, arco e flecha, paraciclismo, atletismo, natação, kart adaptado e futebol de mesa. A ASSAMPAR conta atualmente com quinze integrantes que compõem a direção da associação, a qual ainda não está registrada conforme todos os requisitos legais. No entanto, compete destacar que a associação tem como meta a regularização das suas atividades até o final do corrente ano.

Para o levantamento dos dados, foi utilizado um instrumento de coleta de dados elaborado pela própria autora, em forma de entrevista semiestruturada. Com o intuito de responder aos objetivos propostos, a pesquisa foi dividida em duas etapas, sendo a primeira com dez questões abertas para o gestor do projeto "Tampinha Paratleta" da ASSAMPAR, e a segunda etapa com dez questões abertas para as instituições educacionais, delimitando-se 
às escolas privadas da cidade de Santa Maria/RS que apoiam o projeto. Atualmente, cinco escolas privadas de Santa Maria/RS participam como apoiadoras do projeto, das quais quatro retornaram com o agendamento para responder às entrevistas. Sendo assim, a amostra do estudo corresponde a $80 \%$ da população objeto do estudo, correspondente à segunda etapa.

As entrevistas foram realizadas entre os meses de abril e maio de 2019, envolvendo uma amostra de quatro pesquisadas de uma população total de cinco escolas privadas, que atuam efetivamente como colaboradoras do projeto; compete destacar que as entrevistas foram gravadas e, após, transcritas na íntegra. Os dados extraídos foram colocados em forma de quadros, retratando na íntegra as respostas obtidas pelos participantes. Após análise dos dados, a pesquisadora visou a analisar os resultados, com o intuito de responder aos objetivos propostos pelo estudo.

\section{Discussão e Resultados}

Com propósito de alcançar os objetivos apresentados pelo presente estudo, os resultados estão divididos em duas etapas. A primeira etapa aborda os resultados apresentados pela associação e, na sequência, os resultados obtidos com as escolas privadas que apoiam o projeto na cidade de Santa Maria/RS.

Dessa maneira, foram realizadas entrevistas com o gestor da ASSAMPAR, que será denominado como D.S., e com as quatro escolas privadas apoiadoras do projeto, que serão denominadas E1, E2, E3 e E4, com a finalidade de preservar suas identidades. Os resultados serão apresentados na forma de quadros, descrevendo, na íntegra, as respostas obtidas.

\subsection{Análise dos resultados obtidos com a ASSAMPAR - Associação Santa-mariense Paradesportiva}

A fim de responder aos resultados da pesquisa, primeiramente, apresentam-se as respostas obtidas através da entrevista realizada com D.S., que é o fundador e atual gestor (diretor) da ASSAMPAR. D.S. possui quarenta e cinco anos, ensino médio completo, e é o idealizador e realizador do projeto "Tampinha Paratleta". De acordo com os dados extraídos das redes sociais do projeto, verifica-se que o objetivo central é coletar tampas 
plásticas e lacres de latas e, com isso, reverter o valor da reciclagem na aquisição de materiais e equipamentos destinados ao paradesporto.

Para melhor compreensão dos fatos abordados com o gestor da ASSAMPAR, optou-se em dividir a análise da entrevista em quatro quadros, como descritos a seguir. $\mathrm{O}$ Quadro 1 apresenta a descrição do projeto na visão do gestor, onde buscou-se transcrever os motivos que levaram D.S. a criar a associação.

\begin{tabular}{|c|c|}
\hline PESQUISADOR & PESQUISADO \\
\hline $\begin{array}{l}\text { A entrevista teve início com a } \\
\text { seguinte indagação: “O que é a } \\
\text { ASSAMPAR”? }\end{array}$ & $\begin{array}{l}\text { Para D.S., "a ASSAMPAR tem por finalidade promover os esportes } \\
\text { adaptados nas diferentes modalidades, porque existem pessoas com } \\
\text { deficiências diferentes umas das outras". }\end{array}$ \\
\hline Como surgiu a ideia do projeto? & $\begin{array}{l}\text { Conforme D.S., "a ideia do Projeto Tampinha Paratleta surgiu a partir da } \\
\text { necessidade de captação de recursos através da Associação, e até mesmo } \\
\text { de receber apoio de empresas e colaboradores. Baseado em outras } \\
\text { campanhas já realizadas no estado do RS, de recolhimento de tampinhas e } \\
\text { lacres com intuito de arrecadar fundos para compra de cadeira de rodas, o } \\
\text { projeto foi apenas adaptado na fundamentação de juntar tampinhas e lacres } \\
\text { para venda e, através dos recursos arrecadados, investir na compra de } \\
\text { material paradesportivo". }\end{array}$ \\
\hline $\begin{array}{l}\text { Porque a ASSAMPAR criou o } \\
\text { projeto "Tampinha Paratleta"? }\end{array}$ & $\begin{array}{l}\text { D.S. fala que "criou o projeto com a finalidade de angariar fundos para } \\
\text { investimento em material paradesportivo, com intuito de beneficiar pessoas } \\
\text { deficientes com a oportunidade de praticar algum tipo de atividade } \\
\text { esportiva". }\end{array}$ \\
\hline $\begin{array}{l}\text { Quais os objetivos pretendidos } \\
\text { com o projeto? }\end{array}$ & $\begin{array}{l}\text { D.S. afirma: "a Associação tem como objetivos principais do projeto } \\
\text { proporcionar às pessoas com deficiência oportunidades e meios, através da } \\
\text { aquisição de materiais paradesportivos, como cadeira de corrida, bicicleta } \\
\text { adaptada, entre outros, para realização de esportes adaptados. Também a } \\
\text { inclusão social e a percepção da consciência ambiental, no descarte correto } \\
\text { dos lixos". }\end{array}$ \\
\hline
\end{tabular}

Quadro 1: Descrição do projeto. Fonte: elaborado pela autora.

Quanto à descrição da associação, compreende-se que a ASSAMPAR foi criada no intuito de beneficiar os esportes adaptados e a inclusão social, trazendo como projeto pioneiro o "Tampinha Paratleta", o qual surgiu da necessidade da associação em obter fundos para custear equipamentos e custos relacionados à mesma. Percebe-se que o projeto se expandiu e não ficou somente voltado às necessidades das pessoas com deficiência, mas também tomou uma grande dimensão no sentido de despertar a consciência e a percepção das pessoas no contexto socioambiental.

Segundo dados do Instituto Brasileiro de Geografia e Estatística (IBGE) (2016), existem duzentas e trinta e sete mil fundações privadas e associações sem fins lucrativos (FASFIL) no Brasil, mensuradas sob cinco critérios estipulados internacionalmente para delimitar um grupo de organizações com uma identidade própria: serem privadas, sem fins lucrativos, institucionalizadas, autoadministradas e voluntárias. 
Dando sequência à entrevista, buscou-se identificar a participação da comunidade escolar sob a ótica da associação, conforme apresentam-se os resultados obtidos no Quadro 2.

\begin{tabular}{|c|l|}
\hline PESQUISADOR & \multicolumn{1}{c|}{ PESQUISADO } \\
\hline $\begin{array}{c}\text { Como está sendo a participação } \\
\text { da comunidade escolar e } \\
\text { colaboradores no projeto? }\end{array}$ & $\begin{array}{l}\text { D.S. confirma: "está sendo um sucesso, o qual se identifica na busca das } \\
\text { pessoas em querer participar, juntando tampinhas e lacres ou sendo um } \\
\text { ponto de coleta. }\end{array}$ \\
$\begin{array}{l}\text { O envolvimento das pessoas no sentido de criar consciência que, cada } \\
\text { um fazendo a sua parte, estará contribuindo para a inclusão social e } \\
\text { também para o meio ambiente". }\end{array}$ \\
\hline
\end{tabular}

Quadro 2: Participação da comunidade escolar. Fonte: elaborado pela autora.

Constata-se, a partir das afirmações de D.S., que a adesão ao projeto está sendo muito grande, tanto pela comunidade escolar quanto pelos colaboradores, identificando-se, assim, a dimensão e a importância que o projeto tem tomado perante a comunidade em âmbito geral. A adesão em auxiliar projetos sociais, como o da ASSAMPAR, pode-se confirmar conforme reportagem recente do Jornal Zero Hora (2018), que diz que, desde outubro de 2016, todas as entidades participantes de projetos voltados a coletar tampinhas no Estado arrecadaram oitenta e sete toneladas do produto, o que retornou em $\mathrm{R} \$ 167$ mil (cento e sessenta e sete mil reais) para as cinquenta e cinco instituições participantes, ou seja, são quarenta e oito milhões de tampinhas que deixaram de ir para o meio ambiente. Assim sendo, pode-se perceber a importância dos projetos, tanto no âmbito socioambiental quanto econômico. Essa afirmativa confirma-se conforme dados que serão relatados, a seguir, no Quadro 3.

\begin{tabular}{|c|l|}
\hline PESQUISADOR & \multicolumn{1}{c|}{ PESQUISADO } \\
\hline $\begin{array}{c}\text { Quantos pontos de coleta } \\
\text { existem hoje e como é feita a } \\
\text { escolha desses locais? }\end{array}$ & $\begin{array}{l}\text { Segundo D.S., "hoje existem mais de cem pontos de coletas, aumentando } \\
\text { a cada dia a participação. } \\
\text { Para selecionar os pontos de coleta, a única restrição é referente às } \\
\text { escolas, em serem pontos de coleta unicamente internos, devido à } \\
\text { segurança das mesmas; no restante é aberto a novos participantes e } \\
\text { colaboradores". }\end{array}$ \\
\hline $\begin{array}{c}\text { Quantos quilos de material já } \\
\text { foram coletados, como é feita a } \\
\text { divulgação desses dados e qual } \\
\text { destino é dado ao material } \\
\text { recolhido pelo projeto? }\end{array}$ & $\begin{array}{l}\text { D.S. confirma que "até então foram juntadas três toneladas e meia, } \\
\text { somando lacres e tampinhas, e com a venda foram arrecadados R\$ } \\
5.400,00 \text { (cinco mil e quatrocentos reais)". }\end{array}$ \\
\hline $\begin{array}{c}\text { Quais as dificuldades enfrentadas } \\
\text { com as ações do projeto? }\end{array}$ & $\begin{array}{l}\text { D.S. diz que "uma das maiores dificuldades encontradas é a questão } \\
\text { logística, e a própria coleta, devido ao aumento significativo dos postos } \\
\text { de coleta e por haver um número pequeno de pessoas disponíveis para } \\
\text { este trabalho dentro da Associação". }\end{array}$ \\
\hline
\end{tabular}

Quadro 3: Dados do projeto. Fonte: Elaborado pela autora. 
Através da análise dos dados fornecidos pelo gestor, constata-se que, atualmente, estão envolvidos com o projeto mais de cem pontos de coleta, distribuídos entre empresas públicas e privadas, instituições de ensino públicas e privadas (no caso escolas, faculdades e universidades) e, ainda, o envolvimento pessoal da comunidade em geral, de onde foram arrecadadas, até então, três toneladas e meia de lacres e tampinhas, totalizando com a venda o valor de $\mathrm{R} \$ 5.400,00$ (cinco mil e quatrocentos reais). O gestor destaca, ainda, a dificuldade na questão logística em arrecadar os materiais nos pontos de coleta, visto que os membros da associação se constituem em número reduzido diante do aumento significativo desses pontos.

Segundo Gustavo Alvarez (Presidente da América Tampas), o plástico facilitou muito a logística e melhorou a vida das pessoas. Entretanto, sabe-se que, apesar de todos os benefícios, o acúmulo do material traz prejuízos, por isso, a importância da educação ambiental, que irá trazer uma melhora no comportamento sobre a maneira correta de direcionar o resíduo (FOLHA DO MATE, 2018). Diante desses fatos, é possível verificar a importância que o referido projeto tem, tanto no âmbito social quanto ambiental, como pode-se observar na fala do D.S. no Quadro 4.

\begin{tabular}{|c|c|}
\hline PESQUISADOR & PESQUISADO \\
\hline $\begin{array}{l}\text { Quais contribuições o projeto } \\
\text { visa a proporcionar no contexto } \\
\text { socioambiental? }\end{array}$ & $\begin{array}{l}\text { Na fala de D.S.: "primeiramente a certeza do reaproveitamento do } \\
\text { material recolhido através do Projeto, ter a certeza de que de alguma } \\
\text { forma foi evitado de ser jogado no lixo. Não se tem noção do quanto o } \\
\text { impacto da campanha está abrangendo no sentido de as pessoas } \\
\text { reconhecerem o quanto é importante cada tampinha e lacre doados, e } \\
\text { através disso a consciência até mesmo da separação do material } \\
\text { reciclável do lixo orgânico, tudo isso resultado de uma campanha que de } \\
\text { certa forma adquire duplo sentido. Então como contribuições acredito ser } \\
\text { no sentido da consciência criada através da campanha, da importância da } \\
\text { reciclagem, da separação de materiais recicláveis, que de alguma forma } \\
\text { podem contribuir para projetos sociais". }\end{array}$ \\
\hline $\begin{array}{c}\text { Com relação à Educação } \\
\text { Ambiental, quais açôes } \\
\text { sustentáveis você considera mais } \\
\text { importantes? }\end{array}$ & $\begin{array}{l}\text { D.S. diz: "não nasci um defensor da natureza, nem dos direitos das } \\
\text { pessoas com deficiência, mas com o passar do tempo, ao longo da vida } \\
\text { passamos a nos perguntar, mas o que está sendo feito aqui? Ou o que não } \\
\text { está sendo feito? } \\
\text { Hoje percebo que não só através da nossa campanha, muitas coisas mais } \\
\text { estão sendo feitas no sentido de ações sustentáveis e de proteção ao meio } \\
\text { ambiente. Antes do projeto eu, D.S., não tinha o costume de separar o } \\
\text { lixo, o que nos dias de hoje é muito diferente, separo totalmente. Outra } \\
\text { grande preocupação é do portão de casa para fora, onde vejo outro } \\
\text { grande problema, onde a pessoa que coleta teu lixo acaba colocando todo } \\
\text { teu trabalho fora, pois não há essa separação durante a coleta". }\end{array}$ \\
\hline
\end{tabular}

Quadro 4: Contribuições do Projeto. Fonte: elaborado pela autora. 
Quando questionado sobre as contribuições do projeto no contexto socioambiental, o gestor destaca a importância do projeto na conscientização das pessoas em relação à separação do lixo orgânico do lixo reciclável e, através disso, não estarem somente preservando o meio ambiente, como também contribuindo para projetos sociais.

Conforme destaca-se no Art. $5^{\circ}$ da Lei n ${ }^{\circ}$ 9.975, de 27 de abril de 1999, Lei de Educação Ambiental:

Art. $5^{\circ}$ São objetivos fundamentais da Educação Ambiental, dentre outros: IV - o incentivo à participação individual e coletiva, permanente e responsável, na preservação do equilíbrio do meio ambiente, entendendo-se a defesa da qualidade ambiental como um valor inseparável do exercício da cidadania; VII - o fortalecimento da cidadania, autodeterminação dos povos e solidariedade como fundamentos para o futuro da humanidade (BRASIL, 1999, cap. I).

Observou-se, através da análise dos dados obtidos com o gestor D.S., o constante crescimento da campanha desde sua criação e a grande dimensão que esta tomou no sentido de conscientização socioambiental. A seguir, serão apresentados os resultados sob a percepção das escolas privadas participantes do projeto.

\subsection{A percepção das escolas privadas com relação ao projeto Tampinha Paratleta da ASSAMPAR}

No artigo $2^{\circ}$ da Resolução $n^{\circ} 2$, de 15 de junho de 2012, que estabelece as Diretrizes Curriculares Nacionais para a Educação Ambiental, fica claro que a educação ambiental não deve somente intencionar o desenvolvimento individual dos alunos, mas incluir a esse desenvolvimento meios que estimulem as relações com os outros indivíduos e com o meio ambiente (BRASIL, 2012).

\footnotetext{
Art. $2^{\circ}$ A Educação Ambiental é uma dimensão da educação, é atividade intencional da prática social, que deve imprimir ao desenvolvimento individual um caráter social em sua relação com a natureza e com os outros seres humanos, visando potencializar essa atividade humana com a finalidade de torná-la plena de prática social e de ética ambiental (BRASIL, 2012, p. 2).
}

Na sequência, apresentar-se-á a análise das entrevistas realizadas com as escolas apoiadoras do projeto, que serão retratadas em cinco quadros, para melhor compreensão 
dos fatos, conforme descritos a seguir. No Quadro 5, descreve-se sobre a participação e o conhecimento do projeto pelas referidas escolas participantes.

\begin{tabular}{|c|c|}
\hline PESQUISADOR & PESQUISADO \\
\hline \multirow{4}{*}{$\begin{array}{c}\text { Quais os principais motivos que } \\
\text { levaram a instituição a aderir ao } \\
\text { Projeto Tampinha Paratleta e } \\
\text { como tomou conhecimento do } \\
\text { projeto? }\end{array}$} & $\begin{array}{l}\text { E1 diz: "tomamos conhecimento do projeto através de um convite do } \\
\text { D.S. para apoiarmos a ideia e por já termos desenvolvido um trabalho em } \\
\text { conjunto com ele sabendo de sua responsabilidade e seriedade. } \\
\text { Aceitamos de imediato o convite e abraçamos a ideia com alegria". }\end{array}$ \\
\hline & $\begin{array}{l}\text { E2 afirma: "há algum tempo, já participávamos do recolhimento de } \\
\text { lacres de latinhas para auxiliar uma outra instituição na cidade para a } \\
\text { compra de cadeira de rodas para pessoas necessitadas. Tomamos } \\
\text { conhecimento do projeto Paratleta da ASSAMPAR através das redes } \\
\text { sociais (Facebook), e desde então nos dedicamos a auxiliar o projeto pela } \\
\text { abrangência de coleta do material, que não se limita apenas a lacres, mas } \\
\text { também tampinhas plásticas de qualquer tipo". }\end{array}$ \\
\hline & $\begin{array}{l}\text { E3 confirma: "aderimos no intuito de sermos parceiros com este projeto } \\
\text { socioambiental e de inclusão. Tomamos conhecimento do projeto através } \\
\text { de um dos integrantes da ASSAMPAR". }\end{array}$ \\
\hline & $\begin{array}{l}\text { E4 diz que "foi natural por conhecer o D.S. e saber do engajamento dele } \\
\text { para com a inclusão social e a prática de esportes adaptados, e também } \\
\text { por reconhecer a importância dessa Campanha para o desenvolvimento } \\
\text { da consciência socioambiental trazida pelo projeto. Na medida em que a } \\
\text { Campanha foi se consolidando, resolvemos então a participação e hoje } \\
\text { somos mais uma instituição parceira nessa caminhada. Tomamos } \\
\text { conhecimento do projeto através do próprio D.S". }\end{array}$ \\
\hline
\end{tabular}

Quadro 5: Participação e conhecimento do projeto. Fonte: elaborado pela autora.

Quanto à adesão ao projeto pelas escolas, percebe-se que todas afirmam ser um projeto sério no sentido socioambiental e na inclusão social, tornando-se um fator determinante para a própria participação. Pode-se identificar que, em sua maioria, as escolas tomaram conhecimento da campanha através do gestor D.S. ou por outros membros da ASSAMPAR.

Para Tozoni-Reis e Janke (2014), a educação escolar encarrega-se de promover a consciência dos educandos para a compreensão e transformação da realidade, garantindo a transmissão, não mecânica, mas sim ativa, do saber elaborado pela cultura, contribuindo para o entendimento de que mudanças sociais são possíveis. Ao promover a socialização desse saber, a escola proporciona a esses educandos perceberem seu papel de agentes transformadores na sociedade. Na sequência, apresentar-se-ão as contribuições do projeto sob a visão das escolas, conforme descrito no Quadro 6.

\section{PESQUISADOR}

Em sua visão, quais são as principais contribuições do projeto para a sociedade?

\section{PESQUISADO}

E1 reconhece que "é um projeto socioambiental que agrega vários elementos e valores tais como: evita a poluição ambiental; auxilia a angariar recursos para a compra de equipamentos paradesportivos; integra e mobiliza grupos, colégios, comunidades em prol de uma boa 


\begin{tabular}{|c|c|}
\hline & $\begin{array}{l}\text { causa; é de fácil participação, arrecadação; atinge diversos públicos, } \\
\text { idades e diferentes classes sociais; chama a atenção para as pessoas com } \\
\text { necessidades especiais, muitas vezes invisíveis na sociedade. Atinge o } \\
\text { público infantil que é de suma importância por ser de base educativo. } \\
\text { Primeiro porque as tampinhas são coloridas, isto é lúdico. Segundo, nesta } \\
\text { fase da vida, muitos aprendizados ficam consolidados". }\end{array}$ \\
\hline & $\begin{array}{l}\text { E2 diz: "acreditamos que as contribuições do projeto para a sociedade } \\
\text { perpassam por questões socioambientais. Para além dos inúmeros } \\
\text { benefícios para a saúde física, a prática esportiva também favorece a } \\
\text { socialização, elevação da autoestima, auto eficácia e da independência, } \\
\text { estimulando dessa forma a saúde mental de seus praticantes, além de } \\
\text { promover a inclusão social de pessoas com deficiência. Além disso, } \\
\text { estamos contribuindo com o meio ambiente - através do recolhimento de } \\
\text { materiais que muitas vezes são descartados e não são aproveitados para } \\
\text { nenhum outro fim. }\end{array}$ \\
\hline & $\begin{array}{l}\text { E3 fala em "conscientizar sobre pequenas ações voltadas ao cuidado com } \\
\text { o meio ambiente e com o consumo consciente. Principalmente com a } \\
\text { inclusão das pessoas com deficiência na prática de esportes adaptados } \\
\text { individuais ou coletivos". }\end{array}$ \\
\hline & $\begin{array}{l}\text { E4 relata: "em primeiro lugar a questão da sustentabilidade, essas } \\
\text { tampinhas e lacres que estariam sendo jogados no lixo, estão sendo } \\
\text { reaproveitados. Outro fato é que através dessa arrecadação está se tendo } \\
\text { a oportunidade de desenvolvimento de projetos de acessibilidade e de } \\
\text { esporte pra pessoas que tem alguma limitação e não tem oportunidade ou } \\
\text { condições para aquisição dos equipamentos. }\end{array}$ \\
\hline \multirow{4}{*}{$\begin{array}{l}\text { Em relação à questão anterior, } \\
\text { quais as contribuições do projeto } \\
\text { para o meio ambiente? }\end{array}$} & E1 diz: "reciclagem, reutilização, ambiente mais saudável, mais limpo". \\
\hline & $\begin{array}{l}\text { E2 certifica: "como foi dito anteriormente, muitas vezes os lacres e } \\
\text { tampinhas são materiais que são facilmente descartados e as pessoas não } \\
\text { dão a devida atenção ou utilização. O projeto contribui para a reciclagem } \\
\text { destes materiais e destina para o reaproveitamento dos mesmos, } \\
\text { diminuindo o impacto ambiental." }\end{array}$ \\
\hline & $\begin{array}{l}\text { E3 propõe: "conscientizar em ações de descarte deste material da forma } \\
\text { correta e redirecionar o uso das tampinhas e dos lacres para um projeto } \\
\text { socioambiental". }\end{array}$ \\
\hline & $\begin{array}{l}\text { E4 afirma que "seria como já foi mencionado anteriormente, a questão } \\
\text { do lixo, a questão de reverter isso a não ir tudo para a natureza, também } \\
\text { ajudando as empresas de reciclagem. A questão de consciência, } \\
\text { precisamos criar a consciência de que nós estamos num planeta se a } \\
\text { gente cuidar dele". }\end{array}$ \\
\hline
\end{tabular}

Quadro 6: Contribuições do projeto. Fonte: Elaborado pela autora.

\section{Sob a perspectiva das escolas, as contribuições do projeto para a sociedade e o meio}

ambiente destacam-se no sentido de conscientização ambiental, reutilização de materiais, reciclagem e, também, dos benefícios que o projeto traz no âmbito da inclusão social.

Os processos educativos devem enfatizar a relação indissolúvel entre desenvolvimento e ambiente, considerando esse último como um espaço de possibilidades e de satisfações para a vida de cada ser humano, sempre e quando sejam compreendidos e respeitados os equilíbrios ecológicos (PERALTA e RUIZ, 2003, p. 260). 
Dando continuidade à análise, apresenta-se, no Quadro 7, como os colaboradores e/ou alunos reconhecem e valorizam as contribuições do projeto.

\begin{tabular}{|c|c|}
\hline PESQUISADOR & PESQUISADO \\
\hline \multirow{4}{*}{$\begin{array}{l}\text { Seus colaboradores e/ou alunos } \\
\text { reconhecem e valorizam essa } \\
\text { atitude? }\end{array}$} & $\begin{array}{l}\text { E1 confirma que "sim, é visível a preocupação de muitas crianças com } \\
\text { uma simples tampinha, esta não pode ser desperdiçada. Também se } \\
\text { percebe o orgulho com que trazem suas sacolinhas cheias ou com } \\
\text { algumas tampinhas para colaborarem". }\end{array}$ \\
\hline & $\begin{array}{l}\text { E2 diz que "a adesão do projeto na instituição foi positiva. Muitas } \\
\text { pessoas reconhecem, valorizam e estão mobilizadas no recolhimento dos } \\
\text { materiais, embora percebamos que muitas outras ainda desconhecem o } \\
\text { destino das tampinhas e lacres ou "esquecem" de juntar ou guardar, ao } \\
\text { invés de jogar no lixo". }\end{array}$ \\
\hline & $\begin{array}{l}\text { E3 declara que "em parte sim, visto que precisamos de mais ações de } \\
\text { conscientização e tornar cultural o cuidado com o meio ambiente e com o } \\
\text { consumo consciente dos produtos do nosso dia a dia". }\end{array}$ \\
\hline & $\begin{array}{l}\text { E4 fala que "sim, todos receberam e se empenharam em fazer dar certo } \\
\text { aqui dentro da instituição de forma a perceber que deram o real valor a } \\
\text { importância do projeto". }\end{array}$ \\
\hline \multirow{4}{*}{$\begin{array}{c}\text { Como é a adesão de seus colegas } \\
\text { e/ou alunos no projeto? }\end{array}$} & $\begin{array}{l}\text { E1 afirma que “todos estão mobilizados e se sentem confortáveis em } \\
\text { participar. Não é um projeto imposto, é um projeto bem aceito onde } \\
\text { todos se alegram ao saberem das conquistas". }\end{array}$ \\
\hline & $\begin{array}{l}\text { E2 diz que "assim como na resposta anterior, a adesão foi positiva de } \\
\text { maneira geral. Muitas pessoas estão mobilizadas, porém ainda } \\
\text { percebemos que algumas pessoas acabam "esquecendo" de juntar os } \\
\text { lacres ou tampinhas. Acreditamos que isso possa estar relacionado à falta } \\
\text { de consciência sobre o acúmulo de resíduos e importância da reciclagem, } \\
\text { pois ainda é tão automático jogar qualquer coisa no lixo, sem se } \\
\text { preocupar no destino do resíduo". }\end{array}$ \\
\hline & E3 afirma: "tem sido bem significativa". \\
\hline & $\begin{array}{l}\text { E4 fala que "a adesão foi extremamente positiva, bem recebida por } \\
\text { alunos, professores e colaboradores". }\end{array}$ \\
\hline
\end{tabular}

Quadro 7: Reconhecimento e adesão ao projeto. Fonte: elaborado pela autora.

Percebe-se um reconhecimento e adesão ao projeto muito positivos por parte dos alunos, professores e colaboradores das escolas entrevistadas, destacando-se a valorização e o empenho por parte de todos no recolhimento das tampinhas e lacres, de forma a perceber a real importância do projeto e seus benefícios.

Segundo Baganha et al. (2018), a trajetória da escola, na direção da sustentabilidade socioambiental, é um trabalho gradual que requer reorganização do trabalho pedagógico, voltado a repensar o currículo, a gestão, os princípios e a relação estabelecida com a comunidade escolar diante do enfrentamento das desigualdades sociais, a fim de se tornar uma escola inclusiva, justa e solidária. Na sequência, apresentar-se-ão as ações que poderiam ser implementadas a partir do projeto, conforme descritas no Quadro 8. 


\begin{tabular}{|c|c|}
\hline PESQUISADOR & PESQUISADO \\
\hline \multirow{4}{*}{$\begin{array}{l}\text { Na sua visão, que outras ações } \\
\text { poderiam ser implementadas } \\
\text { nesse eixo? }\end{array}$} & $\begin{array}{l}\text { E1 declara que "já implantamos a coleta das garrafas pet (tiramos as } \\
\text { tampinhas antes para este projeto) e dos equipamentos eletrônicos". }\end{array}$ \\
\hline & $\begin{array}{l}\text { E2 dá ideia de "ações que ampliem a coleta para outros tipos de materiais e } \\
\text { que estimulem cada vez mais a inclusão de pessoas com deficiência na } \\
\text { prática de atividades físicas". }\end{array}$ \\
\hline & $\begin{array}{l}\text { E3 propõe "campanhas mais frequentes nas escolas, com projetos sobre o } \\
\text { cuidado com o meio ambiente e com o consumo consciente dos produtos". }\end{array}$ \\
\hline & $\begin{array}{l}\text { E4 confirma que "criar ações e campanhas dentro dessa linha de } \\
\text { solidariedade juntamente com consciência de preservação, devem ser mais } \\
\text { implementadas nas escolas, pois é com as crianças que se obtém maiores } \\
\text { resultados, são nossa fonte inspiradora para que tenhamos adultos mais } \\
\text { responsáveis e conscientes". }\end{array}$ \\
\hline \multirow{4}{*}{$\begin{array}{c}\text { Você recomendaria o projeto para } \\
\text { outros parceiros? Por quê? }\end{array}$} & $\begin{array}{l}\text { E1 afirma que "sim, recomendaria. Porque é um projeto valoroso. Que une, } \\
\text { que ajuda, que aproxima, que traz consigo um ensinamento que não se } \\
\text { encontra nos livros. É ação em conjunto. Não é um fio que nos une, é uma } \\
\text { tampinha! }\end{array}$ \\
\hline & $\begin{array}{l}\text { E2 diz que "já tivemos a oportunidade de recomendar e continuaremos } \\
\text { recomendando porque acreditamos na importância da atividade } \\
\text { física/esporte na vida das pessoas, pelas consequências na saúde física e } \\
\text { mental, e principalmente no impacto na qualidade de vida das pessoas com } \\
\text { deficiência. Além disso, acreditamos no poder de que se cada pessoa fizer } \\
\text { sua parte, recolhendo e separando materiais recicláveis como os lacres e } \\
\text { tampinhas podemos impactar positivamente o meio ambiente". }\end{array}$ \\
\hline & $\begin{array}{l}\text { E3 reconhece que "com certeza, pois não só contribui para o bem social de } \\
\text { outras pessoas como também para o meio ambiente". }\end{array}$ \\
\hline & $\begin{array}{l}\text { E4 confirma que "sim, certamente, achamos uma bela iniciativa, pelas } \\
\text { questões de ser um projeto engajado com uma causa de grande valia, } \\
\text { solidariedade, sustentabilidade e conservação do meio ambiente". }\end{array}$ \\
\hline
\end{tabular}

Quadro 8: Ações do projeto. Fonte: elaborado pela autora.

Quanto às ações do projeto, questionou-se sobre quais outras poderiam ser implementadas nesse eixo, onde destacaram-se ações que ampliem a coleta para outros tipos de materiais, projetos sobre cuidados com meio ambiente, consumo consciente de produtos e campanhas voltadas à solidariedade, já que é através das crianças que se poderá formar um futuro com adultos mais conscientes e responsáveis. Para Ritt e Cagliari (2007, p. 211):

\begin{abstract}
Vivemos em uma sociedade em crise, com falta de objetivos e limites, na qual estrutura-se o homem que vai dominar e o que será dominado. Neste contexto a escola tem que formar cidadãos, promover a participação social e política do ser de modo a perceber-se integrante do processo, com capacidade de agir para modificar e, a partir disso, conquistar seu espaço. Educação Ambiental nessa perspectiva significa ser um mediador de situações de aprendizagem, traduzindoas em conhecimento científico e significativo para o aluno.
\end{abstract}

Prosseguindo às análises, a seguir, no Quadro 9, apresenta-se o detalhamento sobre o destino do material nas instituições antes do projeto, o acompanhamento dos resultados e 
os ganhos que as instituições acreditam ter ao aderir a projetos relacionados às causas socioambientais.

\begin{tabular}{|c|c|}
\hline PESQUISADOR & PESQUISADO \\
\hline \multirow{4}{*}{$\begin{array}{l}\text { Antes do projeto, qual era o } \\
\text { destino desse material na } \\
\quad \text { instituição? }\end{array}$} & $\begin{array}{l}\text { E1 assegura que "iam para o lixo, talvez uma ou outra pessoa já } \\
\text { separasse por conta própria, mas não havia nenhum olhar com este } \\
\text { cuidado". }\end{array}$ \\
\hline & $\begin{array}{l}\text { E2 admite que "antes do projeto, o destino do material ia direto para o } \\
\text { lixo". }\end{array}$ \\
\hline & $\begin{array}{l}\text { E3 diz que "era colocado no lixo ou esporadicamente utilizado para } \\
\text { algum tipo de atividade pedagógica. }\end{array}$ \\
\hline & E4 afirma que "era descartado no lixo". \\
\hline \multirow{4}{*}{$\begin{array}{l}\text { A instituição acompanha os } \\
\text { resultados e as ações feitas pelo } \\
\text { projeto? De que forma? }\end{array}$} & E1 declara: "acompanhamos via internet pela Assampar". \\
\hline & $\begin{array}{l}\text { E2 diz: "acompanhamos os resultados e ações do projeto através das } \\
\text { redes sociais, seja em facebook e instagram". }\end{array}$ \\
\hline & E3 afirma que "via internet". \\
\hline & $\begin{array}{l}\text { E4 afirma que "sim acompanhamos os resultados pelo facebook, pelas } \\
\text { redes sociais no geral". }\end{array}$ \\
\hline \multirow{4}{*}{$\begin{array}{l}\text { Quais ganhos a Instituição } \\
\text { acredita ter ao aderir a projetos } \\
\text { relacionados às causas } \\
\text { socioambientais? }\end{array}$} & $\begin{array}{l}\text { E1 certifica que "um colégio tem uma missão muito importante que é } \\
\text { ensinar, mas não se restringe a isso. Os ensinamentos se revelam também } \\
\text { pelo exemplo e pela postura de seus integrantes. Desde a direção até o } \\
\text { zelador, porteiro, etc. Todos têm que estar envolvidos. E é assim que este } \\
\text { projeto acontece e se tornou um sucesso. Todos abraçando com alegria a } \\
\text { causa. Portanto nosso maior ganho é um legado, um exemplo que ficará } \\
\text { na memória de muitos". }\end{array}$ \\
\hline & $\begin{array}{l}\text { E2 propõe "estimular a consciência ambiental e reciclagem de materiais; } \\
\text { valorizar o empenho e trabalho dos integrantes da Assampar; estimular o } \\
\text { trabalho em equipe (se cada pessoa fizer sua parte em juntar os materiais, } \\
\text { juntos teremos muito mais material para ajudar); valorizar e estimular a } \\
\text { inclusão social de pessoas com deficiência; estimular a prática de } \\
\text { esportes; estimular projetos da própria cidade". }\end{array}$ \\
\hline & $\begin{array}{l}\text { E3 consolida "fomentar a cultura do cuidado com o meio ambiente e com } \\
\text { o "outro" e assim criar ações mais frequentes de humanização". }\end{array}$ \\
\hline & $\begin{array}{l}\text { E4 acredita que "por estar em um meio educacional, quanto mais a } \\
\text { Instituição e os alunos estiverem envolvidos com essas causas, em prol } \\
\text { da sociedade, que irão reverter em benefícios para a mesma, mais } \\
\text { vantajoso será para a própria Instituição, pois estará de certa forma } \\
\text { contribuindo para a formação de pessoas mais conscientes e engajadas no } \\
\text { cuidado ao ser humano e ao meio ambiente em que se vive". }\end{array}$ \\
\hline
\end{tabular}

Quadro 9: Vantagens da instituição em aderir ao projeto. Fonte: elaborado pela autora.

Sobre as vantagens das escolas em aderir ao projeto, destacou-se os benefícios de estimular a consciência ambiental e social, o estímulo ao trabalho em equipe e a inclusão social, dado que se percebe que, anterior ao projeto, esse material (tampinhas e lacres) era jogado no lixo e, a partir da adesão à campanha, tornou-se um desafio em prol de algo que veio contribuir beneficamente à mudança de hábitos por parte de todos. Segundo os gestores entrevistados, os resultados da campanha são acompanhados pelas redes sociais da ASSAMPAR. 
A educação requer que educadores e educandos desenvolvam em conjunto uma interpretação qualitativamente melhor a que traziam antes de iniciar o processo educativo, auxiliando na identificação e no estímulo das mudanças necessárias para retroceder os problemas socioambientais enfrentados na atualidade. Envolver-se ativamente na busca de tais mudanças não depende unicamente de uma maior consciência e do desenvolvimento de habilidades dos educandos, mas também de fazer crescer as diversas dimensões que representam uma pessoa: afetiva, corporal, intelectual, de conduta etc.; importa reconhecer o caráter integral dos indivíduos que compartilham do processo educativo (PERALTA e RUIZ, 2003).

\section{Considerações Finais}

Através da educação ambiental, por meio da qual podem ocorrer as mudanças do modo como o homem se relaciona com o meio, bem como os principais conceitos relacionados ao tema desse estudo, buscou-se identificar a importância de ações como as desenvolvidas pela ASSAMPAR. A educação ambiental pode ser aplicada nas mais diversas atividades e é através desse processo educativo que é possível melhorar a sociedade e o ambiente.

O presente estudo teve como objetivo geral identificar quais são as principais contribuições que o Projeto "Tampinha Paratleta" traz para o contexto socioambiental da comunidade de Santa Maria/RS. Observou-se, de um modo geral, que o projeto foi muito bem aceito e encontra-se em constante crescimento, atualmente contando com um grande número de colaboradores comprometidos com pontos de coletas e divulgação. Percebe-se a expansão do projeto não somente voltado às necessidades das pessoas com deficiência, mas também na preocupação de despertar a consciência e a percepção no contexto socioambiental, tornando-se positivo no âmbito da educação ambiental e da inclusão social.

Quanto aos objetivos específicos, primeiro buscou-se descrever como ocorrem as ações realizadas pelo projeto, destacando-se que o este foi criado no intuito de beneficiar os esportes adaptados, a inclusão social e a percepção da consciência ambiental. Conta, hoje, com mais de cem pontos de coleta, de onde já foram arrecadadas mais de três toneladas de tampinhas e lacres, que deixaram de ir para o meio ambiente. É importante salientar que uma das maiores dificuldades enfrentadas pelo projeto se encontra na questão 
logística e no recolhimento das tampinhas e lacres nos postos de coleta, devido ao número reduzido de pessoas disponíveis para esse trabalho dentro da associação.

Dentro das contribuições socioambientais que o projeto proporciona à comunidade, vale ressaltar o estímulo à consciência socioambiental determinada pela campanha através da separação e reciclagem de materiais, que podem ser revertidos em benefícios sociais, destacando-se a amplitude tomada pelo projeto nos eixos de educação ambiental e inclusão social.

O estudo delimitou-se na análise de percepção nas escolas privadas da cidade de Santa Maria/RS que participam como apoiadoras do projeto, verificando-se que está sendo de grande aceitação e de extrema importância os benefícios trazidos pela adesão ao projeto, dado que despertou o estímulo à consciência ambiental, à reciclagem de materiais, ao trabalho em equipe, à receptividade e até à curiosidade em relação aos limites e potencialidades das pessoas com deficiência física.

Conclui-se que a educação ambiental e a inclusão social formam um processo lento e delicado diante do sistema educacional vigente, porém é preciso que se acredite e se busque mudanças por meio de atitudes grandes e pequenas, individuais e coletivas. É preciso haver persistência para promover ações que contribuam para a transformação na concepção individual de cada pessoa, através da conscientização sobre os fatos. Sabe-se que um estudo nunca chega à sua finalidade, assim, como proposta para estudos futuros, sugere-se a reaplicação do questionário aos demais segmentos que apoiam o projeto desenvolvido pela ASSAMPAR.

\section{Referências}

ALENCASTRO, M. S. C. Empresas, Ambiente e Sociedade: Introdução a Gestão Socioambiental Corporativa. Curitiba: Inter Saberes, 2012.

ANDRADE, R. O. B.; TACHIZAWA, T.; CARVALHO, A. B. Gestão Ambiental: Enfoque estratégico aplicado ao desenvolvimento sustentável. São Paulo: Makron Books, 2006.

BARBIERI, J. C.; SILVA, D.; Educação Ambiental na formação do administrador. São Paulo: Cengage Learning, 2011.

BARBOSA, G. S. O Desafio do Desenvolvimento Sustentável. Revista Visões, Rio de Janeiro, v. 1, n. 4, - Jan./Jun. 2008. 
BARGANHA, D. E.; VIEIRA, E. R.; MORTELLA, R. D.; ROSA, M. A. Educação ambiental rumo à escola sustentável. Curitiba: SEED: UTP, 2018.

BRASIL. Ministério da Educação. Conselho Nacional de Educação. Resolução n ${ }^{\circ} 2$ de 15 de junho de 2012. Estabelece as diretrizes curriculares nacionais para a educação ambiental. Brasília, 2012. Disponível em: http://conferenciainfanto.mec.gov.br/images/conteudo/iv-cnijma/diretrizes.pdf. Acesso em: 12 jun. 2019.

BRASIL. Lei de Educação Ambiental. Lei 9.795/1999 de 27 de abril de 1999. Dispõe sobre a educação ambiental, institui a Política Nacional de Educação Ambiental e dá outras providências. Brasília, 1999. Disponível em: http://www2.mma.gov.br/port/conama/legiabre.cfm?codlegi=321. Acesso em: 12 jun. 2019.

CAMPANER, É. C. S.; ARAÚJO, G. M. S.; PINHEIRO, G. M. S. Gestão Ambiental como Responsabilidade Social das Organizações. São Paulo: Lins, 2009.

DAL FORNO, M. A. R. Fundamentos em Gestão Ambiental. SEAD/UFRGS. Porto Alegre: Editora da UFRGS, 2017.

DALFOVO, M. S.; LANA, R. A.; SILVEIRA, A. Métodos quantitativos e qualitativos: um resgate teórico. Revista Interdisciplinar Cientifica Aplicada, Blumenau, v. 2, n. 4, p. 01-13, Sem. II 2008.

DIAS, R. Gestão Ambiental: Responsabilidade Social e Sustentabilidade. São Paulo: Atlas, 2011.

FONSECA, J. J. S. Metodologia da pesquisa científica. Fortaleza: UEC, 2002.

GERHARDT, T.; SILVEIRA, D. Métodos de Pesquisa. Porto Alegre: UFRGS, 2009

GIL, A. C. Como elaborar projetos de pesquisa. São Paulo: Atlas, 2007.

IBGE 2016. Número de ONGs e associações no Brasil cai 16,5\% entre 2010 e 2016. Disponível em: https://g1.globo.com/economia/noticia/2019/04/05/numero-de-ongs-e-associacoes-no-brasil-cai165percent-entre-2010-e-2016-diz-ibge.ghtml. Acesso em: 15 mai. 2019.

LEFF, E. Saber ambiental: Sustentabilidade, Racionalidade, complexidade, poder. Rio de Janeiro: Vozes, 2011.

O VALOR DAS TAMPINHAS. Folha do Mate, Venâncio Aires, 24 nov. 2018. Disponível em: https://folhadomate.com/noticias/local/o-valor-das-tampinhas/. Acesso em: 13 jun. 2019.

OLIVEIRA, L. R.; MEDEIROS, R. M.; TERRA, P. B.; QUELHAS, O. L. G. Sustentabilidade: da evolução dos conceitos à implementação como estratégia nas organizações. Produção, v. 22, n. 1, p. 70-82, jan. / fev. 2012.

PERALTA, J. E.; RUIZ, J. R. Educação popular ambiental: para uma pedagogia da apropriação do ambiente. In: LEFF, Enrique (coord.). A complexidade ambiental. São Paulo: Cortez, 2003. 
PHILIPPI, JR. A.; PELICIONI, C. M. F. Educação ambiental e sustentabilidade. São Paulo: Manole, 2005.

QUANTO VALE A TAMPINHA QUE VOCÊ DOA. Zero Hora. Porto Alegre, 24 ago. 2018. Disponível em: https://gauchazh.clicrbs.com.br/portoalegre/noticia/2018/08/quanto-vale-a-tampinha-quevoce-doa-cjl8blo1g045g01n05hmnpv0j.html. Acesso em: 15 jun.2019.

RITT, C. F.; CAGLIARI, C. T. S. Meio ambiente: um direito humano fundamental. In: GORCZEVSKI, C. et al. Direitos humanos, educação e meio ambiente. Porto Alegre: 2007.

SARTORI, S.; LATRÔNICO, F.; CAMPOS, L. M. S. Sustentabilidade e Desenvolvimento Sustentável: Uma Taxonomia no Campo da Literatura. Ambiente e Sociedade. São Paulo: v. XVII, n. 1, p. 1-22, jan.- mar. 2014.

SEIFFERT, M. E. B. Gestão Ambiental: Instrumentos, Esferas de Ação e Educação Ambiental. São Paulo: Atlas, 2011.

TACHIZAWA, T. Gestão Ambiental e Responsabilidade Social Corporativa. São Paulo: Atlas, 2011.

TOZONI-REIS, M. F. C.; JANKE, N. Políticas públicas para a educação no Brasil: Contribuições para compreender a inserção da educação ambiental na escola pública. In: TOZONI-REIS, M. F. C.; MAIA, J. S. S. (Org.). Educação ambiental a várias mãos: educação escolar, currículo e políticas públicas. Araraquara: Junqueira \& Marin, 2014. p. 110-124. 